\title{
側壁反射を用いて発生させた方向スペクトル波の 位置的定常性
}

\author{
正員 世良 亘* 正員 梅 田直 哉** \\ Homogeneity of Directional Irregular Waves with Side-Wall Reflections \\ by Wataru Sera, Member Naoya Umeda, Member
}

\begin{abstract}
Summary
For model experiments of nonlinear behaviors of a ship running in realistic ocean environment, it is necessary to generate short-crested irregular waves that have a specified and stationary directional spectrum in a model basin. However, the measurements of the waves generated by the double-summation method with side-wall reflections indicated that the variance of wave elevation is not stationary in space. Therefore, the authors carried out comprehensive numerical experiments to compare the double-summation method and single-summation one both with side-wall reflections. As a result, it is concluded that singlesummation method even with side-wall reflections can be regarded as practically stationary in space but the double-summation method cannot.
\end{abstract}

\section{1. 粕 言}

船舶の転覆は線型予測に頼ることのできない非線型現 象であり、その現象を再現するためには今日でも模型実 験を行う必要がある。またその場合、自然界で発生する 海洋波は短波頂不規則波であるため、多数の方向成分を 持つ不規則波を想定した実験が行えることが望ましい。 このため、多分割造波装置を水槽に設置して方向スペク トル波を発生させる実験が近年行われるようになった。

このとき、航走する船舶はその位置を刻々変化させる ため、水槽内の一部ではなく全面に方向スペクトル波を

\footnotetext{
*神戸商船大学

"大阪大学大学院工学研究科
}

原稿受理 平成 12 年 7 月 10 月

秋季講演会において講演 平成 12 年 11 月 16,17 日
発生させねね゙ならず、その波の特性についても位置的に 変動しないことが望まれる。これらの問題を解決する手 法として、竹沢らにより側壁反射を利用して水槽全面に 方向スペクトル波を発生させる方法が考案され ${ }^{1)}$ 、また 笠原らの数值実験 ${ }^{2}$ により Double-Summation 法でも 㥶用上位置的に定常であるとの結論が得られた。

これに対し、梅田らが水産工学研究所において、側 壁反射を利用して Double-Summation 法により発生 させた造波実験 ${ }^{3)}$ では、方向スペクトルの形状は位置に よりほとんど変動しないものの、その分散では位置的 変動が観測されている（Fig.1）。実際、側壁反射があ ると同一周波数について複数の方向角の成分波が存在 し、理論上は位置的定常とはならない4)。そこで、御手 洗らはさらに詳細な水槽実験での計測と数値計算により この問題を追求し、分散の変動原因は側壁反射ではなく Double-Summation 法にあると結論づけている4)。し かし、Single-Summation 法により造波される不規則 


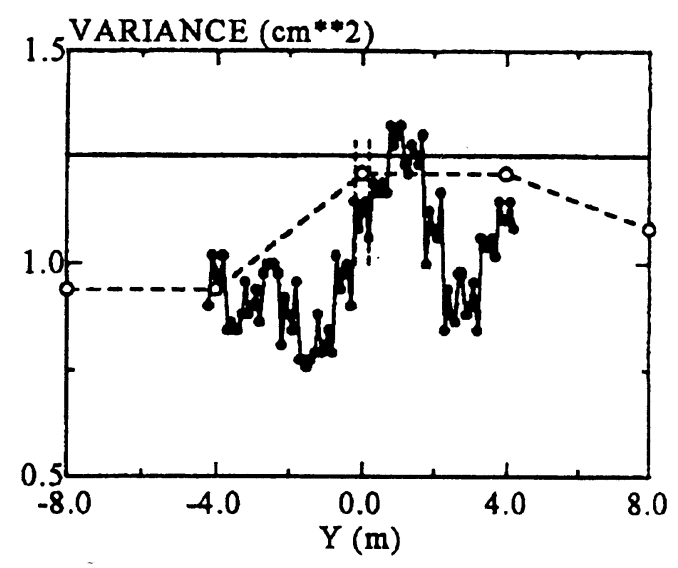

Fig. 1 Distribution of variance of measured wave elevation $(\mathrm{x}=15 \mathrm{~m}$; white circles : from Ref.3) ; black circles : from Ref.4) ; line : specific value)

波がどのような特性を持つかについては確認されておら ず、その時の側壁反射の影響についても検討は行われて いない。

この船舶の水槽試験法上残された重要な課題5)を解 決するために、本研究では Single-Summation 法及び Double-Summation 法による方向スペクトル波の数值 計算を行い、その結果を比較検討する事により方向スペ クトル波の位置的定常性と側壁反射の影響について考察 するものである。

\section{2. 方向スペクトル波の数值計算法}

\subsection{Double-Summation 法}

海洋波を模擬した方向スペクトル波は、周波数と方向 角を変化させたランダム位相の規則波を線形重ね合わせ することにより表現できると仮定すると、その水面変位 を次式のように表すことができ、Double-Summation 法としばしば呼ばれる。

$$
\begin{array}{r}
\zeta(x, y, t)=\sum_{i=1}^{I} \sum_{j=1}^{J} a_{i j} \cos \left[\frac { \omega _ { i } ^ { 2 } } { g } \left(x \cos \theta_{j}\right.\right. \\
\left.\left.+y \sin \theta_{j}\right)-\omega_{i} t+\epsilon_{i j}\right]
\end{array}
$$

ここで、 $I ， J$ は角周波数と方向角の分割数、 $g$ は重力 加速度、 $x, y$ は空間固定座標、 $t$ は時間である。忘た、 $a_{i j}, \omega_{i}, \theta_{j}, \epsilon_{i j}$ は成分波の振幅、角周波数、方向 角、位相で次式に示す 2 次元スペクトラムによって与え られる。

$$
\begin{gathered}
a_{i j}=\sqrt{2 S\left(\omega_{i}, \theta_{j}\right) \Delta \omega_{i} \Delta \theta_{j}} \\
S\left(\omega_{i}, \theta_{j}\right)=S\left(\omega_{i}\right) D\left(\theta_{j}\right)
\end{gathered}
$$

$S\left(\omega_{i}\right)$ は 1 次元の周波数スペクトル、 $D\left(\theta_{j}\right)$ は方向分布 密度関数である。

この方法は、原理上同一周波数で異なる方向角の成分 波が存在するため、波の分散が位置的定常にはならない とされてきた6)が、竹沢ら ${ }^{1)}$ や笠原ら 2 による钼測及び 数値計算では Double-Summation 法でも十分な方向数 をとれば位㯰的に定常とみなし得るとの結果が報告され ている。実際の海面を表現するにはこちらの方法が自然 であると考えられ、船舶分野の水槽試験では一般的に用 いられている。

\subsection{Single-Summation 法}

これに対して Single-Surnmation 法とは、ある周波 数の成分波は一方向のみに進むという条件を施し、位置 的定常性を理論的に保証する造波方法で、以下の式で表 現される。

$$
\begin{gathered}
\zeta(x, y, t)=\sum_{i=1}^{I} a_{i} \cos \left[\frac { \omega _ { i } ^ { 2 } } { g } \left(x \cos \theta_{i}\right.\right. \\
\left.\left.+y \sin \theta_{i}\right)-\omega_{i} t+\epsilon_{i}\right] \\
a_{i}=\sqrt{2 S\left(\omega_{i}, \theta_{i}\right) \Delta \omega_{i} \Delta \theta_{i}} \\
S\left(\omega_{i}, \theta_{i}\right)=S\left(\omega_{i}\right) D\left(\theta_{i}\right)
\end{gathered}
$$

この方法はある 1 地点において 1 つの周波数の波は単 一に存在するのみであるから、十分な時間の計測を行え ば必ず位置的定常性が保たれるはずである。しかし、側 壁反射の影響を受ける水槽内においては反射波として同 一周波数の波が存在しうるため、必ずしも位膡的定常性 が保たれるかどうか仿わからない。また、波の周波数を 作為的に調整していることから、実際の海面状況を模擬 するとは言い難い面がある。

\section{3 設定条件}

上記の 2 種類の計算方法を用いて、御手洗らが水槽実 験を行ったとき4)と同様の条件設定で数値計算を行った。 なお、計算においては、造波機のユニット幅を無限小と 理想化して上述の式を用いた。計算に使用した座標系を Fig.2 に示す。

本計算では、周波数 $0.5 \sim 3.0 \mathrm{~Hz}$ 爷分割された区間 のスペクトラムの面積が一定となるように不等間隔に 200 分割し、方向角は-70〜 70 度を等間隔に 71 分割 して行った。また、各成分波の位相は $[-\pi \sim \pi]$ の一様 


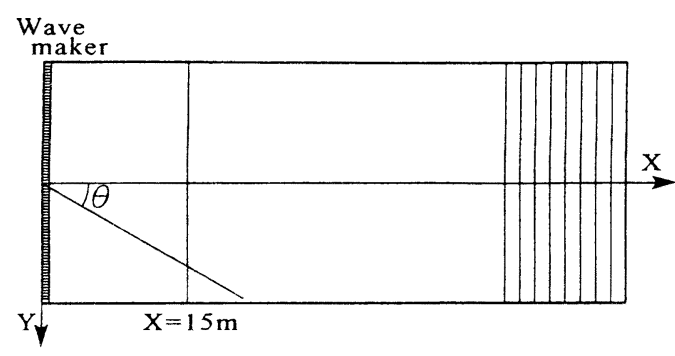

Fig. 2 Coordinate system

乱数によって与えられている。発生する波の有義波高は $4.5 \mathrm{~cm}$ 、平均波周期は 1.0 秒とし、周波数スペクトルは ITTC(1978)、そして方向分布関数はコサインの 4 乗分 布を使用した。

計算点は $\mathrm{x}=15 \mathrm{~m}, \mathrm{y}=-12.5 \sim 12.5 \mathrm{~m}$ の区間を $0.1 \mathrm{~m}$ 間隔で分割した 251 点とし、計算時間間隔は 0.1 秒と した。

また、側壁反射については完全反射を考えている。こ のため、ある地点での波を計算する場合各方向角につい て壁に当たった反射波かどうかを調べ、反射波が届いて いる場合は壁に対して線対称となる方向角の周波数成分 の波を重ね合わせることになる。たとえば、 $\theta=60$ 度 の成分波が側壁反射を 1 回起こして届いている場合は、 造波機の位置で $\theta=-60$ 度方向に発生した波が届い ているので、その成分波の振幅、周波数、位相で計算を 行う。

そして、数值計算により求められた定点における波 高の時系列からその分散を求め、各計算点の分散を比較 することにより位㯰的定常性について検討を行うことと する。

\section{3. 計算結果}

\section{1 計算時間と時系列の分散の亲動}

まず最初に、側壁反射が存在しない状况での DoubleSummation 法及び Single-Summation 法による方向 スペクトル波の数值計算を、計算時間を変化させて行い その影響について調べた。同じ乱数を用いて計算時間を 変化させたとき0時系列の分散を、それぞれ Fig.3 及び Fig.4 に示す。 どちらの計算方法においても計算時間が 長くなるほど分散の変動幅は小さくなったが、DoubleSummation 法では 2000 秒を超えると大きな変化はな くなった。この時の変動幅は約 40 \%程度である。そ れに対し、Single-Summation 法では同じ計算時間で も Double-Summation 法より変動幅が小さく、さら

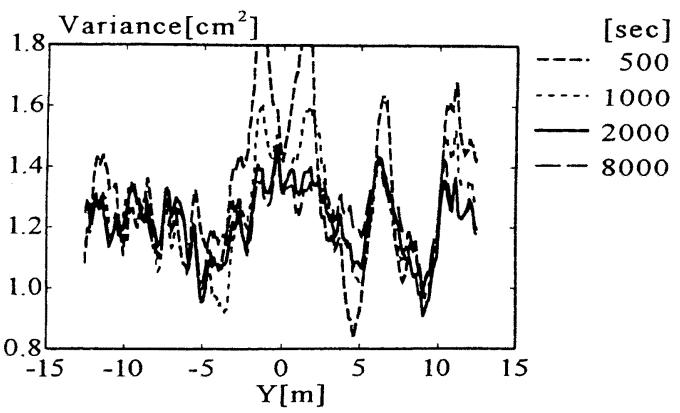

Fig. 3 Distribution of variance of wave elevation generated by DoubleSummation without side-wall reflections $(x=15 \mathrm{~m})$

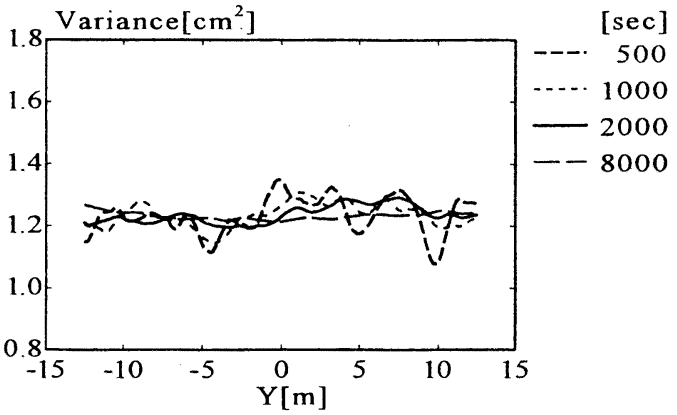

Fig. 4 Distribution of variance of wave elevation generated by SingleSummation without side-wall reflections $(\mathrm{x}=15 \mathrm{~m})$

に計算時間が長くなるにつれて変動幅が縮小している。 計算時間が 2000 秒で変動幅が約 $10 \%$ 、8000 秒では 約 $2 \%$ である。これは、波の成分数が同じ場合 SingleSummation 法の方が Double-Summation 法よりも周 波数間隔が狭くなり、それだけ定常となるのに時間がか かるためと考えられる。すなわち、分散を得る際に成分 波間の積を求める過程で各周波数の差に当たる周波数の 時間による変動が生じる。周波数の間隔が小さくなると、 この差の周波数での変動が収束するために長時間を要す ることとなる。本来は、それぞれの方法で変動幅が定 常となるところまで計算するべきとも考えられるが、計 算が長時間かかること及ひ両者の計算時間をそろえた状 態で比較を行いたいことから今回は計算時間を 2000 秒 として後の計算を行い、その結果を比較検討することと した 


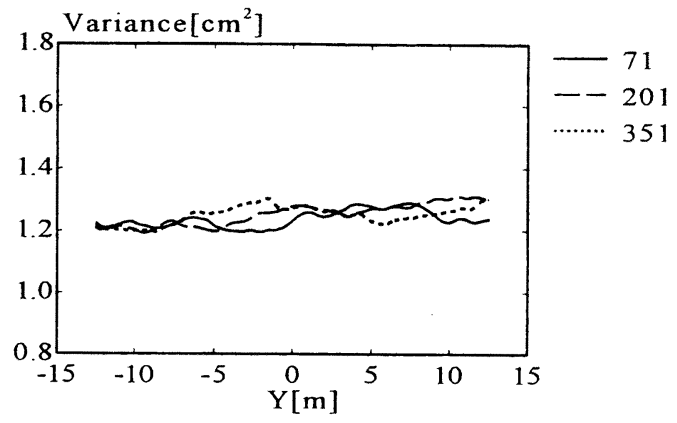

Fig. 5 Effect of number of component angles on variance of wave elevation generated by Single-Summation without side-wall reflections

\subsection{Single-Summation 法における方向分割数と 分散の㚆動}

Double-Summation 法による計算では、実用で使用 されるような範囲では方向分割数を増やしても分散の位 置的変動に対しては影響が見られなかったと報告されて いる4)。そこで、Single-Summation 法において位置的 変動に対し方向分割数による影響があるかどうかを調べ るため、Single-Summation 法で 201 分割と 351 分割 で計算を行い、71 分割の結果と比較した。

側壁影響がない場合の各分割数の計算結果を Fig.5、 側壁影響がある場合の結果を Fig.6 に示す。どちらの 場合でも、方向分割数を増加させてもその位置的変動 量の分散は同梯の変動幅を示しており、方向分割数の増 加により位置的定常性が現れるという現象は DoubleSummation 法と同様 Single-Summation 法において もみられない。また、側壁影響の有無についても変動幅 に対する影響忟みられなかった。

\section{3 水棈の長手方向における分散の㚆動}

水槽の幅方向だけでなく長手方向に対しても同様の計 算を行い、各造波方法による違いと側壁反射の影響につ いて比較した。計算点は $\mathrm{y}=10 \mathrm{~m}, \mathrm{x}=5 \sim 45 \mathrm{~m}$ の区間を $0.1 \mathrm{~m}$ 間隔で分割した 401 点とし、計算時間間隔 0.1 秒 で計算時間は 2000 秒とした。Double-Summation 法 と Single-Summation 法についてそれぞれ側壁反射が ない場合の計算結果を Fig.7、側壁反射がある場合の計 算結果を Fig. 8 に示す。水槽の幅方向の場合と同様に、 長手方向でも側壁影響による変動幅への影響は見られず、 造波方法の違いにより大きな差が現れていることが分 かる。

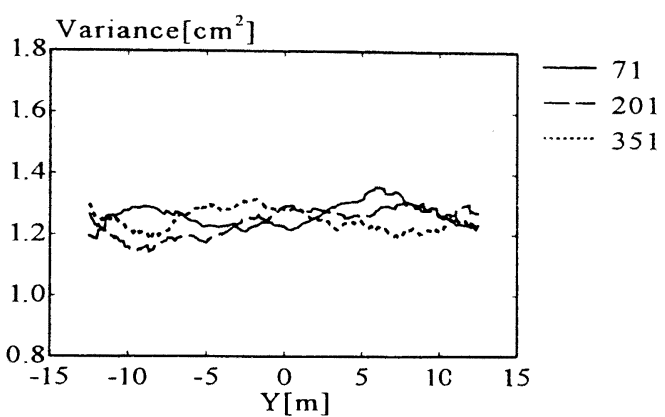

Fig. 6 Effect of number of component angles on variance of wave elevation generated by Single-Summation with side-wall reflections

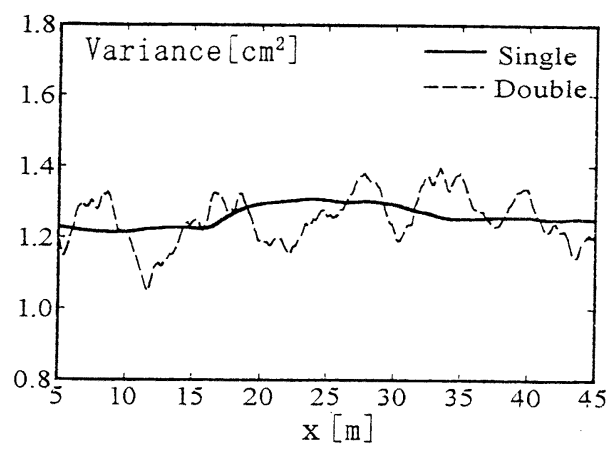

Fig. 7 Distribution of variance of wave elevation generated by Double-Summation and SingleSummation without side-wall reflections $(y=10 \mathrm{~m})$

\section{4 畞壁反射による分散の変動}

側壁反射の影響があるかどうかを論じる場合、ある初 期位相の組に対する一つの結果だけで評価するのは十分 ではない。そこで、50 通りの初期位相の組を与えて計算 を行い、それぞれの計算結果について次のような統計量 $S^{2}$ を計算し、その分布図を作成することで位置的定常 性に対する側壁反射の影響を評価することとした。

$$
S^{2}=\frac{1}{N} \sum_{n=1}^{N}\left(v_{n}-\tilde{x}\right)^{2}, \quad \tilde{x}=\frac{1}{N} \sum_{n=1}^{N} v_{n}
$$

ここで、 $N$ は計測点数、 $v_{n}$ は各計測点における波高の 分散の值である。これにより作成される分布図を Fig.9 に示す。図中の点は確率分布関数の標本值を表しており、 縦軸の值は累積の最大值が 1 となるように正規化されて 


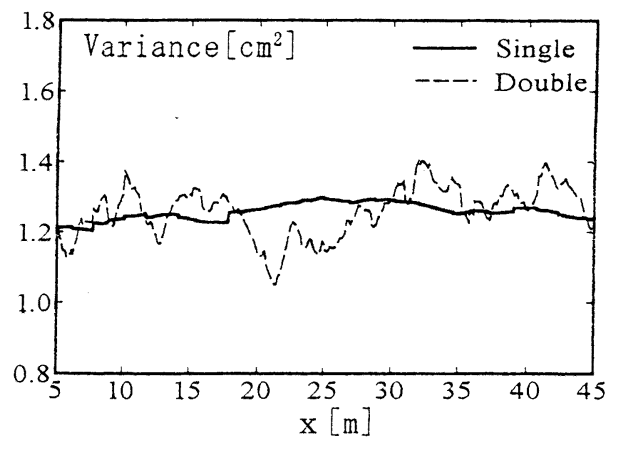

Fig. 8 Distribution of variance of wave elevation generated by Double-Summation and SingleSummation with side-wall reflections $(y=10 \mathrm{~m})$

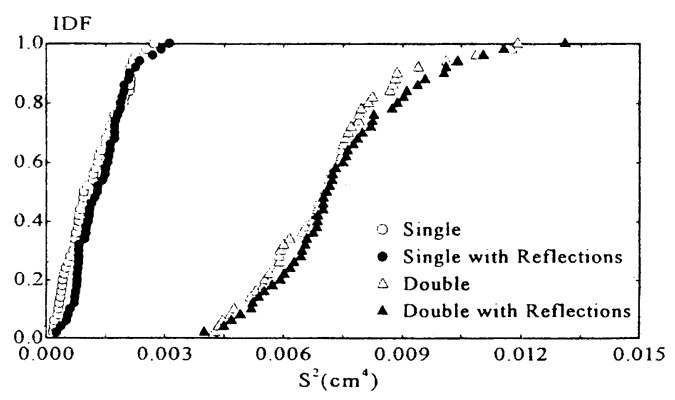

Fig. 9 Distribution function of sample variance of wave elevation

いる。この図より、Double-Summation 法と SingleSummation 法のどちらの場合でも、側壁反射があるな しに関わらずその分布形状に違いがみられないことがわ かる。また、Double-Summation 法に比べて SingleSummation 法の変動は著しく小さい。

Single-Summation 法では、さらに前述のように計測 時間を増加させるとこの変動がより小さくなっていくこ とより、位置的定常性を有するとみなしてもさしつかえ ないと考えられる。計算時間が 8000 秒の時の DoubleSummation 法と. Single-Summation 法の結果の一例 を Fig.10に示す。

\section{4. 結 言}

本研究における数値実験の結果、方向スペクトル波の 発生における位置的定常性について以下の結論を得た。

（1）実用で使用されるような 70 以上の方向角をもつ

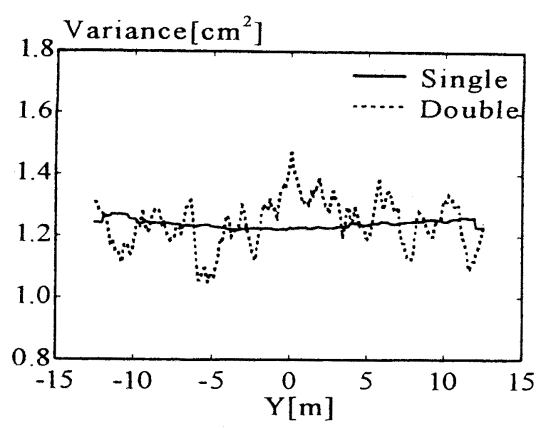

Fig. 10 Comparison of Double-Summation and Single-Summation for variance of wave elevation with sidewall reflections $(t=8000 \mathrm{sec})$

よう生成された波で位置的定常性を調べるには、 数千周期単位での計測、計算が必要である。

(2) Double-Summation 法により発生させた不規則 波では、位置的定常であるとみなすことはでき ない。

(3) Single-Summation 法により発生させた不規則 波は、位置的定常であるとみなすことができる。

（4）側壁反射は、位置的定常性についてはほとんじ影 響を及ぼさず、Single-Summation 法では側壁 反射がある場合でも位置的定常であると実用上み なすことができる。

以上の結果に関し、今後 Single-Summation 法を用 いた水槽実験による詳細な計測での確認が期待される。 また、実験に際してどのような不規則波の発生法を使用 すべきかは、その実験の目的を十分考虑して決定されね ばならない。

終わりにのぞみ、本研究に対して神戸商船大学井上欣 三副学長より御高配を受けたこと、本研究の一部は文部 省科学研究補助金 (課題番号 12450400 : 研究代表者 長 谷川和彦教授）によることを記し、関係各位に謝意を表 する次第である。

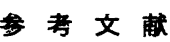

1）竹沢誠二，小林顕太郎，笠原昭夫：長水槽内で発生 させた方向スペクトル波について，日本造船学会論 文集，163，pp.222-232，1988

2）笠原昭夫，前田久明，増田光一，吉野博之：2次元 人工不規則水波の発生法と解析法（第 3 報），関西 造船協会誌, 216, pp.93-99, 1991 
3）梅田直哉, 山越康行 : 側壁反射を用いて角水槽内に 発生させた方向スペクトル波の特性, 日本造船学会 論文集, 174, pp.297-307, 1993

4) 御手洗哲司, 梅田直哉: 側壁反射を用いて角水槽内 に発生させた方向スペクトル波の位置的特性, 関西 造船協会誌, 229, pp.205-210, 1998

5）平山次清, 冨田宏, 新開明二, 石田茂資, 馬蜜, 小 川剛孝：応答から見た波浪の諸問題，船体運動およ びその制御と海象（運動性能研究委員会・第 13 回 シンポジウム), 第 1 編, 日本造船学会, pp.68-75, 1997

6) Jefferys, E. R. : Directional Seas should be Ergodic, Applied Ocean Research, Vol.9, No.4, 1987 